\title{
Bio-Cng as Transportation Fuel for Automobiles
}

\author{
K.Sunil ${ }^{1}$, MohammedFazilhussian ${ }^{2}$, Ch.Saipriya ${ }^{3}$, P.Bharathkumarreddy ${ }^{4}$ \\ (1,2,3,4 Mechanical engineering, Sreenidhi institute of science and technology, India)
}

\begin{abstract}
Bio gas is the natural gas which is produced by anaerobic digestion of the organic mass or biodegradable matter. It can be used as a fuel in order to supply energy. This paper deals with the production of biogas from different sources and its conversion into BIO CNG which can be replaced with the current fossil fuels so that the automobiles can be energized, Simultaneously this also helps in the reduction of emissions of harmful gases into the environment which leads to sustainable living of the mankind.
\end{abstract}

Keywords: BIO-CNG, biogas, alternative fuels, compressed biogas.

\section{Introduction}

Due to the increased population and advancements made in the automotive sector the usage of the fossil fuels has been increased drastically all around the world which led to the pollution of the environment and also global warming. The emissions due to fossil fuels contains many harmful and greenhouse gases like $\mathrm{CO}, \mathrm{H}_{2} \mathrm{~S}, \mathrm{NO}_{\mathrm{x}}$, $\mathrm{CO}_{2}$ etc. India's consumption of crude oil is approximately 3.2 million barrels per dayIndia produces 1.4 metric tons of Carbon Dioxide per capita annually. World consumption of crude oil is approximately 86.9 million barrels per day. World reserves of crude oil are reported to be 687.43 billion barrels. At the present rate of consumption the reserves are expected to last for 25 more years [1]. So the increased concern regarding the fossil fuels has led to the research for an alternative fuel like biogas According to an Ag STAR report, a 1MW anaerobic digestion facility can produce approximately 3 million $\mathrm{kWh}$ of electricity per year, which is enough to supply power to more than 200 homes [2]. Another study evaluated energy crops for biogas production in the EU-25 ( the 25 Member States of the European Union).It showed that 320 million tons of crude oil equivalents(COE)could be produced with crop rotations that integrate the production of food ,feed , raw materials (e. g . oils ,fats, organic acids), which would provide up to $96 \%$ of the total energy demand of cars and trucks In the EU-25 [3]. In China, biogas production from small-scale biogas digester has increased from approximately1.8_109 $\mathrm{m}^{3}$ in 1996to1.0_1010 $\mathrm{m}^{3}$ in 2007 (equivalentto1.1_1011 $\mathrm{kWh}$ electricity), while biogas production from medium-and large-scale biogas projects has increased from approximately1.2_1011 $\mathrm{m}^{3}$ in 1996 to $6.0 \_1012 \mathrm{~m}^{3}$ in 2007 (equivalentto6.3_1013 $\mathrm{kWh}$ electricity)

Biogas is a chemical mixture of methane carbon dioxide nitrogen hydrogen sulphide and oxygen which are in the proportions as tabulated below [5]

\begin{tabular}{|l|l|}
\hline Contents & $\%$ percentage \\
\hline Methane & $50-75$ \\
\hline Carbon dioxide & $25-50$ \\
\hline Nitrogen & $0-10$ \\
\hline Hydrogen & $0-1$ \\
\hline Hydrogen Sulphide & $0-3$ \\
\hline Oxygen & $0-0.5$ \\
\hline
\end{tabular}

II. Biogas Production

The bio gas production can be done in many ways the most popular among them are by

1) animal dung

2) Food waste

3) Municipality waste

4) Agricultural waste

\section{Cleaning Of Biogas}

The biogas generated by the above mentioned process contains a lower hydrocarbons. If biogas is used for production of heat and electricity via heat and power (CHP) unit, only water and $\mathrm{H} 2 \mathrm{~S}$ removal is required. However, using biogas transportation fuel conversion has strict requirements on its composition. So this process of increasing the methane content in the biogas is known as cleaning of biogas Cleaning of biogas can be done by the following methods [6] 
1) Pressurized Water scrubbing

2) Pressure swing adsorption

3) Amine adsorption

4) Membrane permeation

\section{1) Pressurized water scrubbing:}

Pressurized water scrubbing (PWS) isthemostcommonlyused biogas cleaning method. This method takesadvantageofthehigher watersolubilityof $\mathrm{CO}_{2}$ and $\mathrm{H}_{2} \mathrm{~S}$ compared toCH $\mathrm{CH}_{4}$, thereby separating bothCO $\mathrm{C}_{2}$ and $\mathrm{H}_{2} \mathrm{~S}$ simultaneouslyfrombiogaswitha high efficiency. Aschematic representation ofthismethod is shown in the below fig.

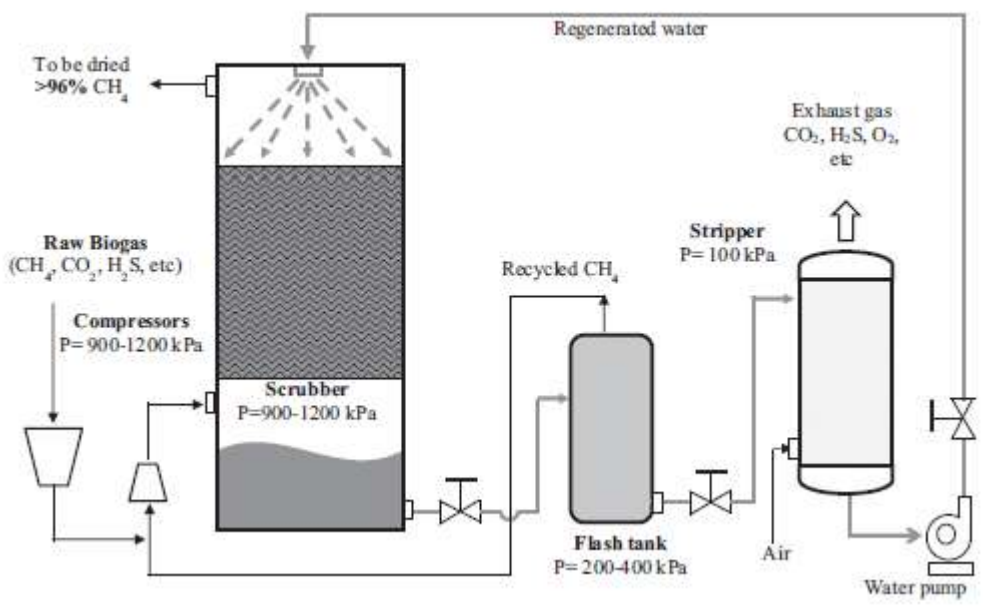

To increase theabsorptionofCO $\mathrm{O}_{2}$ and $\mathrm{H}_{2} \mathrm{~S}$, biogasis usually compressedto900-1200kPaandahighsurfacearea packing mediaisused.Insidethescrubber,biogas flowscounter- currently (opposite direction) towaterthatissprayedfromthetopofscrubber,andthe absorptionprimarilyoccursonthesurfaceofthepackingmedia. Cleaned biogas can contain $96 \% \mathrm{CH}_{4}$ afterdrying.

The advantages of this method is it doesn't uses any chemicals and it simultaneously removes both $\mathrm{CO}_{2}$ and $\mathrm{H}_{2} \mathrm{~S}$. Its disadvantage is that it uses large amount of water. A recent study has proved that if the pressure content applied is increased then the water usage can be decreased.

\section{2) Pressure swing adsorption:}

Pressure swing adsorption (PSA) uses the adsorbent's differences in gas adsorption rates to capture preferred gases (e.g. $\mathrm{CO}_{2}, \mathrm{O}_{2}, \quad$ andN $\mathrm{N}_{2}$ ) at a high pressure, and then releases the adsorbents at a lowpressuretoregeneratetheadsorbentfor asubsequent adsorption cycle. Commonlyusedadsorbentsare zeolite, carbon molecular sieve, silica gel, and activated carbon, due totheirlow cost, largespecific areaandpore volume, and excellentthermal stability. Theseadsorbentsaredesignedtohaveaspecific pore sizethusenablingselectiveadsorptionof moleculesthatare smaller thanthedesignedporesize.

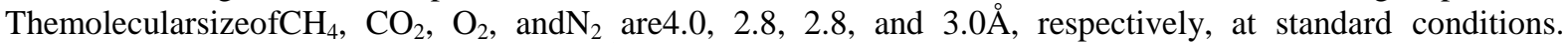
Therefore, anadsorbentwithaporesizeof3.7Åisable tocapture $\mathrm{CO}_{2}, \mathrm{O}_{z}$, andN $\mathrm{N}_{2}$, butnotCH $\mathrm{H}_{4}$, therebycleaningthe biogas. Thismethodwas first employedin1989forCH4 enrichment frombiogaswhenPandeandFabiani used anatural zeolite used extensivelyforbiogascleaning.ThePSAadsorptionand desorption process usually includesfourstepsas represented in schematic diagram .In thepressurizedvessel(700-800kPa,step1), $\mathrm{CO}_{2}$ and othersmall-sizegasesareadsorbed, whiletheenriched $\mathrm{CH}_{4}$ leaves from thetopofthevessel.Whentheadsorbentissaturatedby adsorbents, thebiogas flowsto another vessel.Itusuallyneeds four ormore vessels operatingatthesametimetocreatea continuous operation, whichreducestheenergyneededforgascompression. When a vessel becomes saturated, it goes through a depressurization step in which the pressure is reduced to around atmospheric condition (100kPa, step2).Gas released in this step contains both impurities and methane, and is recycled through the desorption vessel. The pressure of the vessel is then further decreased to near vacuum $(0 \mathrm{kPa}$, step3), which de-adsorbs captured impurities, regenerating the adsorbents. The gas that leaves the vessel in this step mainly consists of $\mathrm{CO}_{2}, \mathrm{~N}_{2}$ and $\mathrm{O}_{2}$. The pressure is built up in (step4) for a subsequent cleaning cycle. 


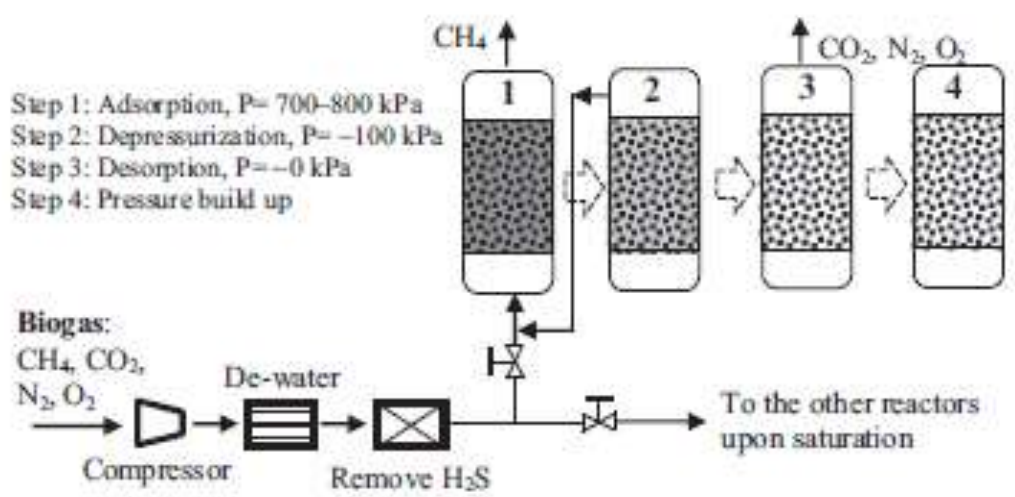

\section{3) Amine adsorption:}

Amine solventhasahighabsorptionselectivityof $\mathrm{CO}_{2}$; therefore, isoftenusedtoseparate $\mathrm{CO}_{2}$ from gasstreams.Amine absorptiontechnologywasoriginallydevelopedfor separating $\mathrm{CO}_{2}$ from coal firedpowerplant flue gasintheearly1980s, and laterwasadoptedasabiogascleaningtechnology.Commonly used solventsarealkanolamines, suchasmonoethanolamine (MEA),

diethanolamine(DEA)ormethyldiethanolamine(MDEA), among whichMEA is the mostwidelyemployedsolventforlow pressure absorption Thesesolventsnotonlyenhance $\mathrm{CO}_{2}$ absorptioncapacitybutalsoreducecorrosionproblems.The reactionsduringadsorptionanddesorptionprocessesareshown below.

AbsorptionofCO2: $\mathrm{RNH}_{2}+\mathrm{H}_{2} \mathrm{O}+\mathrm{CO}_{2} \rightarrow \mathrm{RNH}_{3}{ }^{+}+\mathrm{HCO}_{3}^{-}$

DesorptionofCO2: $\mathrm{RNH}_{3}+\mathrm{HCO}_{3} \rightarrow \mathrm{RNH}_{2}+\mathrm{H}_{2} \mathrm{O}+\mathrm{CO}_{2}$

WhereR Isan organic component.Forexample, Ris - $\left(\mathrm{CH}_{2}\right)_{2} \mathrm{OH}$ for

MEA.Theabovereactionsaremainlygovernedbytemperatureand pressure.Lowtemperatureandhighpressurefavorabsorption,

whilehightemperatureandlowpressurepromotedesorption. A schematicdiagramofamineabsorptionanddesorption is shown below Biogas is usuallycompressedat $600-700 \mathrm{kPa}$ before feeding intotheabsorptionreactor.Inthe absorption phase, $\mathrm{CO}_{2}$ and $\mathrm{someH}_{2} \mathrm{~S}$ gasdissolveintothesolvent, whilehigh-purity $\mathrm{CH}_{4}$ gas leavesthereactor.The $\mathrm{CO}_{2}$-rich solventisthentransferred totheregenerationreactor.Toacceleratedesorption, hightemperature (115-1251C) andrelativelylowpressure (140-170kPa) are usually employed. After desorption, a high-purity $\mathrm{CO}_{2}$ product can be collected and the $\mathrm{CO}_{2}$ lean solvent is returned to the absorption reactor. The main disadvantage of this method is its high demand for amine.

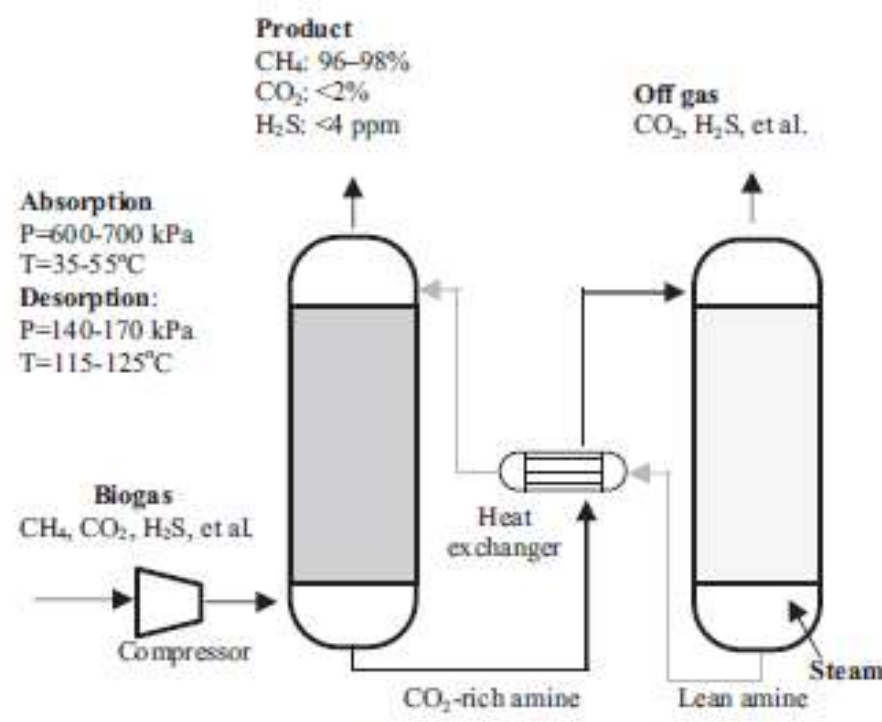

Abserption

Desorption 


\section{4) Membrane permeation:}

The design principle of membrane permeation is that under a certain pressure, gases with high permeability (e.g.small molecular size and low affinity) can be transported through the membrane while gases with low permeability are retained. High permeable impurities, such as $\mathrm{CO}_{2}, \mathrm{O}_{2}$, and $\mathrm{H}_{2} \mathrm{O}$, pass through the membrane as permeate, while low permeable $\mathrm{CH}_{4}$ is retained and can be collected at the end of the hollow column. Using membranes for bio gas treatment began in the early 1980s when Kimura and Walmet made polymer membranes and used them to separate a synthetic mixture of $\mathrm{CH} 4$ and $\mathrm{CO} 2$. After decades of development, the membrane permeation method is now known for its safety, scale-up flexibility, simplicity of operation and maintenance, and no requirement for hazardous chemicals. General criteria for evaluating membrane separation are selectivity, pressure drop, $\mathrm{CH}_{4}$ loss, and membrane life span. In 1983, a cellulose acetate spiral-wound membrane was used to treat biogas .Duringthe 18 month trial, $96.5 \% \mathrm{CH}_{4}$ content was obtained.

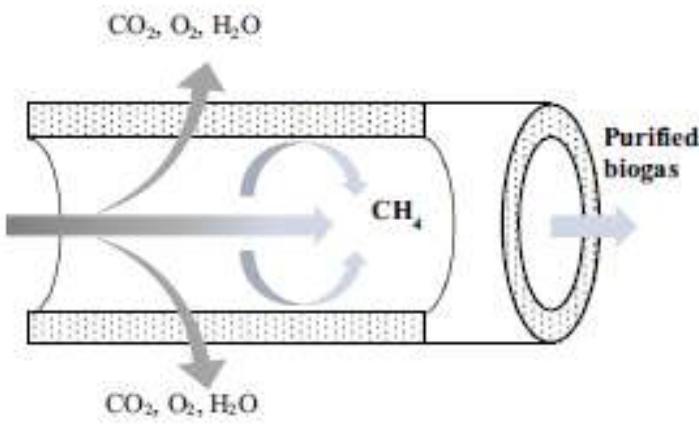

\section{Bio-Cngand Itsstorage:}

The BIO CNGdiffers from CNG in its chemical composition. Even though both the gases contain methane, carbon dioxide, Hydrogen sulphide, nitrogen,oxygen. CNG additionally contains ethane and propane including the above chemicals mentioned. Cleaned (greater than $97 \% \mathrm{CH}_{4}$ purity) biogascan be compressedto produceBIO-CNG, whichisverysimilartoregular CNG. BIO-CNG is alsoknownascompressedbiomethane.

Conversion of biogas into BIO-CNG requires removal of impurities using the four methods as mentioned above Cleaned biogas should contain more than $97 \% \mathrm{CH}_{4}$ and lessthan $2 \% \mathrm{O}_{2}$. BIO-CNGisthen producedbycompressing $(20-25$ $\mathrm{MPa}$ )cleanbiogastolessthan

percentofthevolumeitoccupiesatstandardatmosphericpressure.

CNGstationusuallyiscomposedofanimpurity separation unit, amulti-stagecompressor, andahighpressurestoragetank. Therearetwocommonlyappliedstorage systemsinindustry

1) Bufferstorage

2) Cascadestorage.

Thebuffer storagesystemmaintainsthepressureofCNGintherangeof20.5-

$\mathrm{MPa}$,andprovidesCNGwithamaximumpressureof20MPatoa vehicle'son-boardcylinders.Inthiscase, all filling stationreservoirs areconnectedand maintained atthesamepressure.Thecascade storagesystemistypicallycomposedofthreereservoirswithlow, medium,andhighpressure,respectively,and fillingCNGtoon-board cylinderstakesthreesteps.Thevehicle'son-boardcylindersare firstly connectedtothelowpressurereservoir.Asthepressureinthe reservoirdeclinesandthatintheon-boardcylinderincreases, the gas flow ratedecreases.Whenthe flow ratehasdeclinedtoapre-set level,the system switchestothemediumpressurereservoir,then finallytothehigh-pressurereservoirtocompletethe filling .Oppositely,whenrefillingthereservoirs, thehigh-pressurereservoiris

prioritized,andthenfollowedbythemediumandlowreservoirs.This method ensures that thehighpressurereservoir(usedtocomplete the fill)ismaintainedatamaximumpressurealltimes, ensuringthat vehiclesarealwayssuppliedwiththemaximumamount ofgas.Comparedtothebufferstoragesystem, thecascadesystemconsumes about50\%lessenergybutcharges $20 \%$ lessbiogasandtakesthree times longerto fill .Therefore, thecascadesystemispreferredfor filling fleet vehiclesthatusuallytakeshours(time-fill), whilethe buffer systemmeetstheneedsforfast-fill thatcanbecompleted within five minutes. 


\section{Advantages Ofbio-Cng:}

1) Emissions:one of the major advantages of biogas is its low greenhouse gases emissions. GHG emissions can be reduced up to $90 \%$ with the help of BIO-CNG

When a natural gas driven vehicle is made to run by replacing the fuel with BIO-CNG the following reduction inthe emissions of the GHG (greenhouse gases) has been observed [7]:

\begin{tabular}{|cl|c|}
\hline \multicolumn{2}{|c|}{ Greenhouse gases } & \% reduction in emissions \\
\hline 1) & Carbon monoxide & $70-90$ \\
\hline 2) & Non methane organic gas & $50-70$ \\
\hline 3) & Nitrogen oxides & $75-95$ \\
\hline 4$)$ & Carbon dioxide & $20-30$ \\
\hline
\end{tabular}

2) Calorific value: BIO-CNG which is obtained by cleaning of biogas has a high calorific value when compared to other fuels and it also meets SAE J1616 standards for CNG [8]

\begin{tabular}{|l|l|}
\hline Fuel & Calorific value in $\mathrm{KJ} / \mathrm{Kg}$ \\
\hline CNG & $53000^{*}$ \\
\hline Petrol & $48000^{*}$ \\
\hline Diesel & $44000^{*}$ \\
\hline LPG & $49789^{*}$ \\
\hline BIO CNG & $\mathbf{5 2 0 0 0}^{*}$ \\
\hline
\end{tabular}

* Slightly differs according to their hydrocarbons content

3) Cost:The cost required for the production of BIO-CNG is approximately $50 \%$ of that of petrol and diesel

*estimated cost

\begin{tabular}{|l|l|}
\hline Fuel & Cost (INR) per liter [9] \\
\hline Petrol & $62 /-$ \\
\hline Diesel & $56 /-$ \\
\hline LPG & $64.5 /-$ \\
\hline CNG & $37.2 /-$ \\
\hline BIO CNG & $35^{*} /-[10]$ \\
\hline
\end{tabular}

\section{Conclusion}

Hence by the above benefits which are mentioned BIOCNG can be considered as the perfect replacement for the current fossil fuels like petrol and diesel. more over in a country like India which is one of the most polluted country after China,USAand European nations [11]there is an urgent need for this kind of alternative fuel replacement recently a BIOCNG plant has been established in Mahindra city Chennai in IndiaThe plant will convert 8 tons of food and kitchen waste generated every day at the MWC into 1,000 cubic meter of raw biogas. Further, the raw bio gas can yield $400 \mathrm{~kg}$ per day of purified CNG-grade fuel which is equivalent to a $200 \mathrm{~kW}$ power plant. As a by-product, four tons of organic fertilizer will be produced per day[12].There is more need for this kind of development not only in India but all around the world these kind of activities help in sustainable living of the mankind.

[1]. http://gbes.in/insightsinsights/

\section{References}

[2]. https://www.epa.gov/agstar/learn-about-biogas-recovery\#adwork

[3]. Amon T, Amon B, Kryvoruchko V, Machmuller A, Hopfner-Sixt K, Bodiroza V, et al. Methane production through anaerobic digestion of various energy crops grown in sustainable crop rotations. Bioresour Technol 2007;98: 3204-12. http://www.sciencedirect.com/science/article/pii/S0960852406003117

[4]. Zhang PD, Yang YL, Tian YS, Yang XT, Zhang YK, Zheng YH, et al. Bioenergy industries development in China: dilemma and solution. Renew Sustain Energy Rev 2009;13:2571-9 http://refhub.elsevier.com/S1364-0321(14)00684-4/sbref3

[5]. Wikipediahttps://en.wikipedia.org/wiki/Biogas\#cite_note-11

[6]. Progress and perspectives in converting biogas to transportation fuels byliangcheng Yang a ,Xumeng Ge a,Caixia Wan b, Fei Yu c, Yebo Li http://www.sciencedirect.com/science/article/pii/S136403211400684

[7]. http://biocng.us/benefits/benefits-cng/

[8]. standards.sae.org-J1616

[9]. http://www.mypetrolprice.com/

[10]. Green bricks eco solutionshttp://gbes.in/

[11]. https://en.wikipedia.org/wiki/List_of_countries_by_carbon_dioxide_emissions

[12]. http://www.thehindu.com/news/cities/chennai/mahindra-city-gets-biocng-plant/article8059945.ece 